\title{
Avaliação tecnológica dos sistemas de produção de leite bovino no Cariri da Paraíba ${ }^{1}$
}

\author{
Technological evaluation of systems of milk production in cattle Cariri of Paraiba
}

\author{
MOURA, José Fábio Paulino de ${ }^{2 *}$; PIMENTA FILHO, Edgard Cavalcanti ${ }^{3}$; GONZAGA \\ NETO, Severino ${ }^{3}$; CÂNDIDO, Ebson Pereira ${ }^{4}$
}

\author{
${ }^{1}$ Parte da Tese de Doutorado em Zootecnia do primeiro Autor. \\ ${ }^{2}$ Universidade Federal da Paraíba, Programa de Pós-Graduação em Zootecnia, Areia, Paraíba, Brasil \\ ${ }^{3}$ Universidade Federal da Paraíba, Departamento de Zootecnia, Areia, Paraíba, Brasil \\ ${ }^{4}$ Universidade Federal Rural da Amazônia, Departamento de Zootecnia, Capanema, Pará, Brasil. \\ *Endereço para correspondência: josefabiomoura@hotmail.com
}

\section{RESUMO}

Objetivou-se, com o presente trabalho, gerar subsídios para os avanços quanti-qualitativos do agro-negócio da bovinocultura leiteira no Cariri da Paraíba a partir do conhecimento estrutural e tecnológico das unidades produtivas, em uma amostra de 100 produtores rurais nos municípios de Caturité e Barra de Santana. O questionário foi composto por informações qualitativas e quantitativas, subdivididas em quatro seções, totalizando 49 perguntas. As seções foram identificadas como aspectos de infra-estrutura, tecnológicos, zootécnicos e nutricionais com o intuito de obter informações relacionadas à caracterização da propriedade, ao perfil do produtor e ao nível tecnológico. As variáveis qualitativas foram avaliadas pelo teste qui-quadrado e as quantitativas pelo teste t. Considerou-se, em ambos os casos, o nível de significância de até 5\%. Não foi registrado diferença entre os municípios para as variáveis: área cultivada com palma forrageira, realização de controle zootécnico e a produtividade do rebanho. Foi evidenciada diferença, entre os municípios, para as variáveis: assistência técnica, área da propriedade, número total de vacas, cultivo de sorgo forrageiro, tipo de exploração pecuária, composição genética dos animais, motivos da realização de descarte dos animais, motivos da realização de secagem das matrizes, número de vacas em lactação, oferecimento do concentrado e mineralização do rebanho. As diferenças tecnológicas verificadas neste estudo, entre os municípios do Cariri paraibano, demonstram o grau de pluralidade existente entre os sistemas de produção de leite bovino. Com as informações geradas, é possível o planejamento de ações específicas para cada situação.

Palavras-chave: bovinocultura leiteira, cooperativa, semiárido, variáveis tecnológicas.

\section{SUMMARY}

The aim of the present work, was to generate data for quantitative and qualitative advances in agrobusiness of dairy cattle in Paraíba Cariri from the knowledge of structural and technological production units in a sample of 100 farmers in the municipalities of Caturité and Barra de Santana. The questionnaire consisted of qualitative and quantitative information, divided into four sections totaling 49 questions. The sections were identified as aspects of infrastructure, technological, nutritional and husbandry in order to obtain information related to the characterization of the property, the profile of the producer and the technological level. Qualitative variables were evaluated by chi-square and $t$ test for quantitative variables. It was, in both cases, the level of significance of $5 \%$. No difference was recorded between the municipalities for the following variables: area planted with cactus, holding control livestock and herd productivity. There Was no significant difference between the cities in the following variables: technical assistance, property area, total number of cows, cultivation of sorghum, farm type, genetic makeup of animals and reasons for conducting disposal of animals, reasons for carrying out the drying of the arrays, the number of dairy cows, and mineralization concentrated offering of the herd. The technological differences observed in this study between the municipalities in Cariri, demonstrate the degree of diversity between the production systems of bovine milk. With the information generated, it is possible to plan specific actions for each situation.

Keywords: cooperative, milking cattle, semiarid, technological characteristics. 


\section{INTRODUÇÃO}

É de extrema importância a caracterização técnica de um sistema de produção, identificando as estruturas e os componentes próprios, iniciando um processo que possa melhorar e promover à pecuária, estudando as unidades de produção encontradas em cada subsistema e procurando orientar a tomada de decisões para novas pesquisas.

Foi com estes objetivos que Costa et al. (2008), estudando as condições de produção pecuária da microrregião do Cariri da Paraíba, verificaram que o uso da silagem chegou ao máximo de $11 \%$ em um dos 5 grupos classificados. De acordo com os resultados nessa pesquisa, $14 \%$ das unidades produtivas faziam conservação. No Rio Grande do Norte, de acordo com o diagnóstico da cadeia produtiva agroindustrial da caprinocultura, é pequena a adoção da fenação $13,9 \%$ e ensilagem $13,8 \%$ pelos pecuaristas. A produção média, por estabelecimento, é 3,7ton de feno e de 35,3ton de silagem.

Para Costa et al. (2010), as forrageiras de maior destaque são a palma forrageira (Opuntia ficus-indica), o capim elefante (Pennisetum pupureum) e o capim Buffel (Cenchrus ciliares), onde $42 \%$ dos produtores possuíam em suas unidades produtivas até 1 hectare de palma forrageira, que $18 \%$ dos produtores possuíam entre 1,1 a 2 ha, sendo que apenas 1 produtor $(3 \%)$ possuía de 10,1 a 20ha de palma. A palma é um alimento de grande importância para os rebanhos, notadamente nos períodos de estiagens prolongadas, pois além de fornecer um alimento verde, supre grande parte das necessidades de água dos animais na época de escassez (SILVA \& SANTOS, 2006).

Franca et al. (2011) verificaram que a palma foi a segunda maior forrageira cultivada no sertão baiano, ocorrendo em $66 \%$ das unidades produtivas, sendo a área média de 1,35 ha e que apenas duas famílias tinham áreas com mais de 10ha.
Sobre o fornecimento de concentrado de acordo com o nível de produção dos animais Oliveira et al. (2007), trabalhado com propriedades rurais na Bahia, verificaram que $47 \%$ dos produtores ofereciam concentrado aos animais de acordo com a produção.

A respeito de controle zootécnico, em estudo realizado por Lima et al. (2007), no Estado da Paraíba, foi verificado que apenas $32 \%$ dos produtores realizavam apenas o controle reprodutivo.

Considerando-se a importância da geração de informações para tomada de decisões no contexto atual da pecuária, objetivou-se gerar subsídios para os avanços do agronegócio da bovinocultura leiteira no Cariri da Paraíba.

\section{MATERIAL E MÉTODOS}

Esta pesquisa foi desenvolvida junto a produtores de leite bovino da microrregião do Cariri Oriental da Paraíba, nos municípios de Caturité e Barra de Santana e amparada numa parceria entre $o$ Departamento de Zootecnia da Universidade Federal da Paraíba (DZ/UFPB) e a Cooperativa Agropecuária do Cariri Ltda. (COAPECAL), a qual recebe o leite para beneficiamento em sua usina.

Foi selecionada uma amostra de 100 produtores rurais fornecedores de leite da Cooperativa, o que representava, aproximadamente, $20 \%$ do total de produtores sendo que, de forma aleatória foram escolhidos 50 produtores que residiam no município de Caturité e os outros 50, no município de Barra de Santana, ambos localizados na Mesoregião da Borborema, na Microregião do Cariri Oriental do Estado da Paraíba.

O município de Caturité, com uma área de $118,2 \mathrm{Km}^{2}$, está localizado na latitude $7,38^{\circ}$ e longitude $-36,06^{\circ}$, a uma altitude de 405 metros. O município se caracteriza por apresentar clima semi-árido, com temperaturas máximas de 37 e mínimas de 
$16^{\circ} \mathrm{C}$ e precipitação pluviométrica média de 500mm/anual (AESA, 2007). Os solos predominantes são do tipo Vertissolo Cromado Órtico - VCo (Campos \& Queiroz, 2006), que se caracterizam como quimicamente ricos e argilosos, com mais de 30\% de argila (EMBRAPA, 1999). À $15 \mathrm{~km}$ de distância do açude "Epitácio Pessoa", o município se beneficia com o abastecimento de água. Na zona rural de Caturité se encontra a usina de beneficiamento de leite da COAPECAL, que favorece os produtores locais no processo de coleta do leite e nas ações promovidas pela Cooperativa.

O município de Barra de Santana possui uma área de $351,2 \mathrm{Km}^{2}$ e está situado na latitude $-7,75^{\circ}$ e longitude $-36,31^{\circ}$ e a uma altitude de 520 metros. Apresenta, também, clima semi-árido, com temperaturas máximas de 40 e mínimas de $19^{\circ} \mathrm{C}$ e precipitação pluviométrica média de 400mm/anual (AESA, 2007). Os solos predominantes são do tipo Neossolo Litólico Eutrófico - RLe (CAMPOS \& QUEIROZ, 2006), que se caracterizam por serem rasos, com pequena espessura até a rocha, de cascalhos e fragmentos de rocha no seu perfil, grande susceptibilidade à erosão nas áreas de relevo acidentado (EMBRAPA, 1999). Diferentemente de Caturité, os produtores de Barra de Santana não são beneficiados com abastecimento de água do açude "Epitácio Pessoa", pois está localizado fora do curso das adutoras originadas neste açude. Os produtores de leite deste município não são diretamente favorecidos com as ações da COAPECAL em função da distância de $65 \mathrm{~km}$ da sede da Cooperativa.

Para obtenção das informações, foi aplicado, em cada uma das cem propriedades, no período de 08 a 26 de janeiro de 2007, um questionário adaptado de Guilhermino \& Freitas (2000) e Leite et al. (2004).

O método utilizado foi o da Entrevista Estruturada (GUILHERMINO \& GROSSI, 1996), que se caracteriza pela apresentação ao entrevistado de questões planejadas com a finalidade de obter respostas apropriadas que atendam os objetivos da pesquisa.

As questões, as opções de respostas e a sequência de indagação foram idênticas para todos os entrevistados. Isto foi feito para assegurar que as variações entre as respostas fossem devidas a diferenças individuais e não aos entrevistadores que foram devidamente treinados para a aplicação do questionário.

$\mathrm{O}$ questionário foi composto por informações qualitativas e quantitativas, subdivididas em quatro seções, totalizando 49 perguntas. As seções foram identificadas como aspectos de infra-estrutura, tecnológicos, zootécnicos e nutricionais com o intuito de obter informações relacionadas à caracterização da propriedade, ao perfil do produtor e ao nível tecnológico.

Os dados foram tabulados em planilhas eletrônicas. Para a descrição das variáveis qualitativas, foram utilizadas as frequências de participação de cada resposta apresentada pelos produtores.

As variáveis qualitativas foram avaliadas em função das frequências de respostas entre os municípios, pelo teste quiquadrado. As variáveis quantitativas foram avaliadas, entre os municípios, por estatística descritiva e distribuição de frequência através do teste $t$, utilizando as médias aritméticas, desvio-padrão, o mínimo e o máximo. Em ambos os casos, foi estabelecido o nível de significância de até $\mathrm{P}<0,05$ (SAMPAIO, 2002).

\section{RESULTADOS E DISCUSSÃO}

Verifica-se, na Tabela 1, que a área média das propriedades rurais de Caturité $(53,4$ ha) foi maior $(\mathrm{P}<0,05)$ do que as de Barra de Santana (23,3 ha). Costa et al. (2008), estudando as condições de produção pecuária da microregião do Cariri da Paraíba, verificaram que o tamanho médio das propriedades eram de 50 hectares, sendo que 95\% desta área era 
ocupada com atividade pecuária, principalmente com a produção de leite. Essa diferença aponta para um sistema de produção mais familiar nas propriedades de Barra de Santana, com áreas menores, suficientes apenas para garantir a renda de subsistência da família.
Com relação à área cultivada com palma forrageira (Opuntia ficus-indica), não se verificou diferença $(\mathrm{P}<0,05)$ entre os municípios, com médias de 6,3 e 5,1 hectares, para os municípios de Caturité e Barra de Santana, respectivamente.

Tabela 1. Variáveis quantitativas da bovinocultura leiteira nos municípios de Caturité e Barra de Santana, no Cariri paraibano.

\begin{tabular}{lcrrrr}
\hline \multirow{2}{*}{ Variáveis } & \multicolumn{2}{c}{ Caturité } & \multicolumn{2}{c}{ Barra de Santana } & \multirow{2}{*}{ P } \\
\cline { 2 - 5 } & Média & \multicolumn{1}{c}{ DP } & Média & \multicolumn{1}{c}{ DP } & \\
\hline Área da propriedade (hectare) & 53,4 & 52,8 & 23,3 & 24,5 & 0,0004 \\
Área com palma (hectare) & 6,3 & 7,8 & 5,1 & 4,9 & 0.3328 \\
Área com sorgo (hectare) & 3,3 & 3,7 & 0,0 & 0,0 & $<0,0001$ \\
\hline
\end{tabular}

h.d. $=$ homens-dia; Min. $=$ mínima; Máx. $=$ máxima; $\mathrm{DP}=$ desvio-padrão; $\mathrm{P}=$ probabilidade.

No entanto, ao se observar a relação entre a área plantada com palma e a área total, verificou-se que no município de Barra de Santana $21,9 \%$ da área total das propriedades eram ocupadas com o cultivo de palma forrageira, enquanto que em Caturité essa percentagem era de $11,8 \%$. Com relação à área cultivada com palma forrageira (Opuntia ficus-indica), não se verificou diferença $(\mathrm{P}<0,05)$ entre os municípios, com médias de 6,3 e 5,1 hectares, para os municípios de Caturité e Barra de Santana, respectivamente. No entanto, ao se observar a relação entre a área plantada com palma e a área total, verificou-se que no município de Barra de Santana $21,9 \%$ da área total das propriedades eram ocupadas com o cultivo de palma forrageira, enquanto que em Caturité essa percentagem era de $11,8 \%$. Para Costa et al. (2010), as forrageiras de maior destaque verificadas em seu estudo eram a palma forrageira (Opuntia ficusindica), o capim elefante (Pennisetum pupureum) e o capim Buffel (Cenchrus ciliares), onde $42 \%$ dos produtores possuíam em suas unidades produtivas até 1 hectare de palma forrageira. O tipo de solo predominante em Barra de Santana pode ser limitante para diversas espécies forrageiras; no entanto, a palma apresenta sistema radicular superficial e ramificado que lhe possibilitam um eficiente aproveitamento das chuvas menos intensas, mesmo em solos rasos. A temperatura e a umidade noturna nesta região também proporcionam condições favoráveis ao cultivo das plantas xerófilas que apresentam o sistema CAM (crassulacean acid metabolism), que é o mais importante de todas as adaptações.

Já para o cultivo de sorgo forrageiro (Sorghum bicolor), verificou-se diferença $(\mathrm{P}<0,05)$ entre os municípios. Em Caturité, a área média plantada com sorgo foi de 3,3 hectares, enquanto que em Barra de Santana não se verificou o cultivo desta gramínea em nenhuma propriedade. Este comportamento ocorre, provavelmente, devido ao tipo de solo predominante no município de Barra de Santana impedindo o cultivo do sorgo, cujo sistema radicular pode atingir até $1,5 \mathrm{~m}$ de profundidade e 2,0m em extensão lateral, para buscar nutrientes para sua manutenção. Ou pode ser explicado ainda, por aspectos culturais apresentados pelos produtores de Caturité em produzir forragem para conservar e utilizar posteriormente na alimentação dos animais, o que promove melhores 
condições de enfrentar os períodos de escassez de forragem. Além de que, nesse município, existe um trabalho de assistência técnica promovido pela Cooperativa orientando, principalmente, sobre a importância da conservação de forragens.

$\mathrm{Na}$ Tabela 2, verifica-se que não houve diferença $(\mathrm{P}<0,05)$ entre os municípios em relação à avaliação da funcionalidade das instalações e máquinas. Do total amostrado, $64 \%$ dos produtores responderam que as instalações e máquinas eram insuficientes para a atividade e o seu estado de conservação era considerado regular. A ausência ou as condições precárias da sala de ordenha foram apontadas, pela maioria dos produtores, como principal limitação relacionada às instalações.

Tabela 2. Variáveis qualitativas, para os aspectos tecnológicos da bovinocultura leiteira nos municípios de Caturité e Barra de Santana, no Cariri paraibano.

\begin{tabular}{|c|c|c|c|c|c|c|}
\hline \multirow{2}{*}{ Variáveis } & \multicolumn{2}{|c|}{ Caturité } & \multicolumn{2}{|c|}{ B. Santana } & \multirow{2}{*}{$\%$ Total } & \multirow{2}{*}{$\mathrm{P}$} \\
\hline & $\mathrm{N}$ & $\%$ & $\mathrm{n}$ & $\%$ & & \\
\hline \multicolumn{7}{|c|}{ As instalações e máquinas são suficientes? } \\
\hline Sim & 22 & 44 & 14 & 28 & 36 & \multirow{2}{*}{0,0956} \\
\hline Não & 28 & 56 & 36 & 72 & 64 & \\
\hline \multicolumn{7}{|c|}{ A sala de ordenha facilita a higienização? } \\
\hline Não tem sala de ordenha & 7 & 14 & 35 & 70 & 42 & \multirow{4}{*}{$<0,0001$} \\
\hline Não são adequadas & 12 & 24 & 0 & 0 & 12 & \\
\hline Parcialmente adequadas & 9 & 18 & 6 & 12 & 15 & \\
\hline Totalmente adequadas & 22 & 44 & 9 & 18 & 31 & \\
\hline \multicolumn{7}{|l|}{ Tipo de ordenha: } \\
\hline Manual & 46 & 92 & 50 & 100 & 96 & \multirow[t]{2}{*}{0,0512} \\
\hline Mecânica & 4 & 8 & 0 & 0 & 4 & \\
\hline \multicolumn{7}{|l|}{ Número de ordenhas: } \\
\hline Uma & 3 & 4 & 0 & 0 & 3 & \multirow[t]{2}{*}{0,2130} \\
\hline Duas & 47 & 96 & 50 & 100 & 97 & \\
\hline \multicolumn{7}{|c|}{ Número de pessoas dedicadas à ordenha: } \\
\hline Uma & 27 & 54 & 20 & 40 & 47 & \multirow{3}{*}{0,3929} \\
\hline Duas & 13 & 26 & 21 & 42 & 34 & \\
\hline Três & 10 & 20 & 9 & 18 & 19 & \\
\hline
\end{tabular}

$\mathrm{n}=$ número de resposta ao questionário; $\mathrm{P}=$ probabilidade do teste qui-quadrado.

Verificou-se diferença $(\mathrm{P}<0,05)$ entre os municípios com relação à facilidade de higienização da sala de ordenha e aos processos de higiene realizados no momento da ordenha. Constatou-se que no município de Caturité, 93\% dos produtores dispunham de sala de ordenha em suas propriedades e que $44 \%$ destas eram totalmente adequadas aos processos de higienização. Enquanto que no município de Barra de Santana, apenas 30\% das propriedades possuíam sala de ordenha, sendo que somente $18 \%$ estavam adequadas aos processos de higienização. Considerando o limite estabelecido pela Instrução Normativa 51 (IN51) para CCS, os resultado de análises microbiológicas realizadas por Lopes Junior et al. (2008) nas propriedade do município de Caturité, demonstraram que $90 \%$ das propriedades analisadas estão em conformidade, inclusive para os limites que serão adotados a partir de 2010 na região Nordeste. Com relação à contagem de mesófilos aeróbios, os autores verificam que, aproximadamente, 93\% das propriedades estão em conformidade com o limite estabelecido pela IN51 até o ano de 2010. Portanto, as condições de higienização da produção de leite tem se mostrado eficiente no município de Caturité, havendo a necessidade de um estudo semelhante par Barra de Santana. 
A respeito do tipo de ordenha, verificou-se que $96 \%$ dos produtores questionados, independente do município, ainda adotam a ordenha manual nos seus rebanhos, realizada duas vezes ao dia, na maioria dos casos ocupando apenas uma pessoa. A baixa utilização de ordenha mecânica no Cariri paraibano ocorre, provavelmente, devido ao pequeno tamanho dos rebanhos, possibilitando aos produtores a realização da ordenha manual em um curto intervalo de tempo e ocupando, na maioria dos casos, apenas uma pessoa.

$\mathrm{Na}$ Tabela 3, foi observada diferença $(\mathrm{P}<0,05)$ entre os municípios com relação aos principais volumosos utilizados na alimentação dos animais. No município de Caturité, a dieta volumosa era constituída, principalmente, por palma forrageira $(22 \%)$ e silagem de sorgo (62\%). Enquanto que no município de Barra de Santana, o principal ingrediente volumoso da alimentação dos animais era a palma forrageira $(98 \%)$. Também se registrou diferença $(\mathrm{P}<0,05)$ entre os municípios a respeito da forma como o volumoso era adquirido. No município de Caturité, $78 \%$ dos volumosos eram produzidos na própria fazenda, enquanto no município de Barra de Santana, 44\% produziam o seu próprio volumoso. Essa diferença na produção e utilização dos volumosos ocorre, possivelmente, em função das condições edafo-climáticas mais favoráveis apresentadas pelo município de Caturité, possibilitando uma situação mais propícia a produção de forragem, somado a um trabalho desenvolvido pela Cooperativa, através de assistência técnica, orientando os produtores sobre o volumoso mais adequado para a região.

A respeito da técnica de conservação de forragem, verificou-se diferença $(\mathrm{P}<0,05)$ entre os municípios, constatando-se que em Caturité $76 \%$ dos entrevistados conservam forragens, principalmente, na forma de silagem de sorgo, enquanto que em Barra de Santana, apenas 2\% dos produtores utilizam o processo de ensilagem. $O$ resultado observado no município de Barra de Santana pode ser explicado pelo tipo de solo que predomina naquela localidade, que se caracteriza por ser raso com grande susceptibilidade à erosão o que, provavelmente, dificulta o cultivo de forrageiras apropriadas para a ensilagem. Além disso, não existe um trabalho de assistência técnica para orientar os produtores sobre a importância e/ou quais as tecnologias de conservação de forragens mais adequadas para aquela região. Costa et al. (2008), observaram em seus estudos com caracterização técnica do sistema de produção pecuária da microregião do Cariri da Paraíba, que o uso da silagem chegou ao máximo de $11 \%$ em um dos 5 grupos classificados. De acordo com os resultados obtidos por estes autores, $14 \%$ das unidades produtivas faziam conservação, nota-se que ainda é uma prática muito reduzida, apesar da necessidade de fornecimento de volumoso de boa qualidade na produção de leite.

Verificou-se diferença $(\mathrm{P}<0,05)$ entre os municípios com relação ao oferecimento do concentrado. Foi constatado que no município de Caturité, $86 \%$ dos produtores ofereciam o concentrado às matrizes de acordo com o nível de produção. Enquanto que no município de Barra de Santana, apenas $34 \%$ dos produtores adotavam este procedimento. Também se registrou diferença $(\mathrm{P}<0,05)$ entre os municípios a respeito do momento de fornecimento do concentrado. No município de Caturité, $80 \%$ dos produtores ofereciam o concentrado no momento da ordenha, enquanto no município de Barra de Santana, 52\% dos produtores realizavam esta prática. Valores intermediários foram encontrados por Oliveira et al (2007), trabalhado com propriedades rurais na Bahia, onde verificaram que $47 \%$ dos produtores oferecem concentrado aos animais em produção. $\mathrm{O}$ fornecimento de concentrado de acordo com o nível de produção dos animais é benéfico por amenizar o desperdício de ração e por não comprometer a produção dos animais com oferecimento aquém ou além do exigido pelo metabolismo deles. 
Rev. Bras. Saúde Prod. Anim., Salvador, v.14, n.1, p.121-131 jan./mar., 2013 http://www.rbspa.ufba.br ISSN 15199940

Tabela 3 Variáveis qualitativas, para os aspectos tecnológicos da bovinocultura leiteira nos municípios de Caturité e Barra de Santana, no Cariri paraibano.

\begin{tabular}{|c|c|c|c|c|c|c|}
\hline \multirow{2}{*}{ Variáveis } & \multicolumn{2}{|c|}{ Caturité } & \multicolumn{2}{|c|}{ B. Santana } & \multirow{2}{*}{$\%$ Total } & \multirow{2}{*}{$\mathrm{P}$} \\
\hline & $\mathrm{n}$ & $\%$ & $\mathrm{n}$ & $\%$ & & \\
\hline \multicolumn{7}{|l|}{ Quais principais volumosos que utiliza? } \\
\hline Palma forrageira & 11 & 22 & 49 & 98 & 60 & \multirow{4}{*}{$<0,0001$} \\
\hline Silagem de sorgo & 31 & 62 & 1 & 2 & 32 & \\
\hline Palma e silagem & 4 & 8 & 0 & 0 & 4 & \\
\hline Palma e bagaço de cana & 4 & 8 & 0 & 0 & 4 & \\
\hline \multicolumn{7}{|l|}{ O volumoso é comprado ou produzido? } \\
\hline Produzido na propriedade & 39 & 78 & 22 & 44 & 61 & \multirow{3}{*}{0,0002} \\
\hline Comprado & 5 & 10 & 3 & 6 & 8 & \\
\hline Produzido e comprado & 6 & 12 & 25 & 50 & 31 & \\
\hline \multicolumn{7}{|l|}{ Se faz conservação de forragem, como faz? } \\
\hline Não faz & 12 & 24 & 49 & 98 & 61 & \multirow[t]{2}{*}{$<0,0001$} \\
\hline Silagem & 38 & 76 & 1 & 2 & 39 & \\
\hline \multicolumn{7}{|l|}{ Qual forragem conserva? } \\
\hline Não conserva & 12 & 24 & 49 & 98 & 61 & \multirow{3}{*}{$<0,0001$} \\
\hline Sorgo & 29 & 58 & 0 & 0 & 29 & \\
\hline Milho e sorgo & 9 & 18 & 1 & 2 & 10 & \\
\hline \multicolumn{7}{|l|}{ Concentrado de acordo com a produção: } \\
\hline Sim & 43 & 86 & 17 & 34 & 60 & \multirow{2}{*}{$<0,0001$} \\
\hline Não & 7 & 14 & 33 & 66 & 40 & \\
\hline \multicolumn{7}{|l|}{ Fornece concentrado apenas na ordenha? } \\
\hline Sim & 40 & 80 & 26 & 52 & 66 & \multirow[t]{2}{*}{0,0031} \\
\hline Não & 10 & 20 & 24 & 48 & 34 & \\
\hline \multicolumn{7}{|l|}{ Como faz a mineralização do rebanho? } \\
\hline Por categoria & 9 & 18 & 0 & 0 & 9 & \multirow{3}{*}{$<0,0001$} \\
\hline O mesmo para todos os animais & 32 & 64 & 23 & 46 & 55 & \\
\hline Não faz & 9 & 18 & 27 & 54 & 36 & \\
\hline \multicolumn{7}{|l|}{ Qualidade da água para os animais: } \\
\hline Boa & 49 & 98 & 20 & 40 & 69 & \multirow{3}{*}{$<0,0001$} \\
\hline Regular & 1 & 2 & 19 & 38 & 20 & \\
\hline Ruim & 0 & 0 & 11 & 22 & 11 & \\
\hline
\end{tabular}

$\mathrm{n}=$ número de resposta ao questionário; $\mathrm{P}=$ probabilidade do teste qui-quadrado.

A respeito da mineralização do rebanho foi observada diferença $(\mathrm{P}<0,05)$ entre os municípios. Em Caturité, $82 \%$ dos produtores faziam a mineralização do rebanho, enquanto que no município de Barra de Santana, $46 \%$ dos produtores adotavam este procedimento. A quantidade de produtores que realizavam a mineralização do rebanho é considerada insatisfatória, levando-se em consideração a relevante importância que esta tem para as funções vitais dos animais. Além de que, em ambos os municípios, esse procedimento era realizado de forma incorreta, pois era adotado apenas um tipo suplementação mineral para todas as categorias. Carências minerais podem ocasionar danos aos animais, pois gera uma queda na produtividade, ou seja, prejudica o desenvolvimento, o crescimento, a produção de leite, facilitando o aparecimento de doenças e queda da fertilidade.

Também se registrou diferença $(\mathrm{P}<0,05)$ entre os municípios a respeito da qualidade da água fornecida aos animais. No município de Caturité, $90 \%$ das propriedades disponibilizavam de água de boa qualidade para oferecer aos animais, enquanto no município de Barra de Santana, 40\% apresentavam esta característica.

Foi verificada, na Tabela 4, diferença $(\mathrm{P}<0,05)$ entre os municípios em função da composição genética dos animais, sendo 
que $76 \%$ dos rebanhos do município de Caturité eram compostos por animais com razoável contribuição de genética especializada para leite (3/4 e 7/8 Holandês), enquanto que no município de Barra de Santana, cerca de $50 \%$ dos rebanhos eram constituídos de animais zebus. Atribui-se isso, a localização das propriedades de Caturité em áreas mais favoráveis em termos de clima, solo, pastagem e disponibilidade de água, como também em razão destes produtores serem possuidores de infra-estrutura mais adequada a pecuária leiteira. Além das melhores condições atuais do mercado na região, promovido pela implantação da Cooperativa, que tem estimulado os produtores a produzirem mais através de animais especializados, movidos por melhores condições de pagamento pelo litro de leite produzido.

Tabela 4. Variáveis qualitativas, para os aspectos zootécnicos da bovinocultura leiteira nos municípios de Caturité e Barra de Santana, no Cariri paraibano.

\begin{tabular}{|c|c|c|c|c|c|c|}
\hline \multirow{2}{*}{ Variáveis } & \multicolumn{2}{|c|}{ Caturité } & \multicolumn{2}{|c|}{ B. Santana } & \multirow{2}{*}{$\%$ Total } & \multirow{2}{*}{$P$} \\
\hline & $\mathrm{n}$ & $\%$ & $\mathrm{n}$ & $\%$ & & \\
\hline \multicolumn{7}{|l|}{ Composição genética do rebanho: } \\
\hline Holandesada & 38 & 76 & 12 & 24 & 50 & \multirow{5}{*}{$<0,0001$} \\
\hline Girolanda & 11 & 22 & 12 & 24 & 23 & \\
\hline Azebuada & 1 & 2 & 12 & 24 & 13 & \\
\hline Zebu & 0 & 0 & 11 & 22 & 11 & \\
\hline Outras & 0 & 0 & 3 & 6 & 3 & \\
\hline \multicolumn{7}{|l|}{ Tipo de Exploração Pecuária: } \\
\hline Leite & 35 & 70 & 2 & 4 & 37 & \multirow{4}{*}{$<0,0001$} \\
\hline Leite e cria & 14 & 28 & 1 & 2 & 15 & \\
\hline Leite, cria e recria & 1 & 2 & 42 & 84 & 43 & \\
\hline Leite, cria, recria e engorda & 0 & 0 & 5 & 10 & 5 & \\
\hline \multicolumn{7}{|l|}{ Recebe assistência técnica? } \\
\hline Sim & 5 & 10 & 0 & 0 & 5 & \multirow[t]{2}{*}{0,0218} \\
\hline Não & 45 & 90 & 50 & 100 & 95 & \\
\hline
\end{tabular}

$\mathrm{n}=$ número de resposta ao questionário; $\mathrm{P}$ = probabilidade do teste qui-quadrado.

Com relação ao tipo de exploração pecuária, verificou-se diferença $(\mathrm{P}<0,05)$ entre os municípios, pois se constatou que no município de Caturité, $70 \%$ dos produtores exploravam apenas o leite, enquanto que em Barra de Santana $84 \%$ dos entrevistados exploravam, além do leite, a cria e recria de machos. Independentemente do município. Esses resultados ocorreram, provavelmente, em função do nível de intensificação de algumas propriedades de Caturité, onde na maioria dos casos os bezerros eram vendidos logo após o nascimento, pois os rebanhos eram constituídos de genética especializada a produção de leite, requerendo o descarte precoce dos animais. Já em Barra de Santana, os rebanhos por serem constituídos de animais azebuados, sugerem a necessidade da presença dos bezerros na ocasião da ordenha, garantindo uma maior persistência da lactação.

A assistência técnica também diferiu $(\mathrm{P}<0,05)$ entre os municípios. No município de Caturité, $10 \%$ dos produtores recebiam assistência técnica, enquanto que no município de Barra de Santana, os produtores não têm acesso a este recurso. Esses resultados diferem dos encontrados por Leite et al. (2004), onde registraram que em 69 propriedades produtoras de leite bovino na Paraíba, 75\% delas recebiam assistência técnica oferecida pela EMATERPB. A proximidade dos produtores de Caturité com a sede da COOAPECAL facilita o acesso dos técnicos da Cooperativa e de Instituições parceiras, o que pode explicar a diferença verificada. No entanto, 
a percentagem de propriedades assistidas é muito baixa, mesmo em Caturité, o que se constitui em um grave ponto de estrangulamento do sistema. Nesse sentido, são necessárias políticas públicas que promovam um trabalho de assistência técnica de qualidade ou a contratação desse serviço através de associações de produtores melhores organizadas.

Observam-se na Tabela 5, os resultados da análise das variáveis quantitativas referentes aos aspectos zootécnicos da bovinocultura leiteira no Cariri paraibano. Com relação ao número total de vacas nos rebanhos, verificou-se diferença $(\mathrm{P}<0,05)$ entre os municípios, com médias de 15,8 e 10,4 matrizes nas propriedades de Caturité e Barra de Santana, respectivamente. A diferença da quantidade das vacas entre os municípios pode ser explicada pela distinção das áreas das propriedades existente entre Caturité e Barra de Santana, uma vez que o tamanho da propriedade rural pode está diretamente relacionado com a quantidade de animais, pois a capacidade de produção de alimentos está associada com a área disponível pra o cultivo de pastagens.

Tabela 5. Variáveis quantitativas, para os aspectos zootécnicos da bovinocultura leiteira nos municípios de Caturité e Barra de Santana, no Cariri paraibano.

\begin{tabular}{lrrrrr}
\hline \multirow{2}{*}{ Variáveis } & \multicolumn{3}{c}{ Caturité } & \multicolumn{3}{c}{ Barra de Santana } & \multirow{2}{*}{ P } \\
\cline { 2 - 5 } & Média & \multicolumn{1}{c}{ DP } & Média & DP & \\
\hline Vacas na atividade (cabeça) & 15,8 & 11,0 & 10,4 & 1,0 & 0,0092 \\
Vacas em lactação (cabeça) & 11,7 & 8,9 & 8,3 & 1,0 & 0,0392 \\
Percentual de vacas em lactação & 74,0 & 18,0 & 80,0 & 28,5 & 0,0160 \\
Produção de leite diário (kg) & 141,2 & 126,4 & 81,7 & 10,0 & 0,0044 \\
Produtividade (kg leite/vaca/dia) & 12,0 & 5,4 & 9,8 & 2,5 & 0,0837 \\
\hline Min = mínima; Máx = máxima; DP = desvio-padrão; P
\end{tabular}

Min. = mínima; Máx. = máxima; $\mathrm{DP}=$ desvio-padrão; $\mathrm{P}=$ probabilidade do teste $\mathrm{t}$.

A respeito do número de vacas em lactação e ao percentual destas em relação ao número total de matrizes no rebanho, verificou-se diferença $(\mathrm{P}<0,05)$ entre os municípios, com médias de 11,7 e 8,3 vacas produzindo leite e 74,0 e $80,0 \%$ de matrizes lactantes em relação ao número total, nas propriedades de Caturité e Barra de Santana, respectivamente. A explicação para o maior percentual encontrado de vacas em lactação nos rebanhos de Barra de Santana é de que os produtores deste município permitiam que a secagem das matrizes ocorresse naturalmente em $48 \%$ das propriedades, o que elevou a quantidade de vacas lactantes. Somado ainda ao fato dos rebanhos de Barra de Santana serem constituídos de animais de composição genética azebuada, não havendo tanta preocupação com a secagem destes para evitar problemas como mastite, por exemplo, se comparado aos rebanhos de Caturité.

Embora, a produtividade não tenha apresentado diferença $(\mathrm{P}<0,05)$ entre os municípios, observou-se diferença $(\mathrm{P}<0,05)$ com relação à produção de leite diária, com médias de 141,2 e $81,7 \mathrm{~kg}$ de leite produzido diariamente nas propriedades de Caturité e Barra de Santana, respectivamente. Esses valores apontam para um tamanho relativamente pequeno dos rebanhos bovinos leiteiros no Cariri paraibano, que são constituídos, principalmente, por pequenas unidades de produção familiar e, no caso de Barra de Santana, esta afirmação é mais evidenciada.

A média de produtividade de leite por ha/ano das propriedades do Cariri paraibano, com médias de 965,13 e $1279,85 \mathrm{~kg}$ de leite/ha/ano, para as unidades produtoras de leite bovino de 
Caturité e Barra de Santana, respectivamente, estão aquém do desejado, segundo Schiffler et al. (1999), Lopes et al. (2003) e ao sugerido por Gomes (2005), Gomes (2002), da necessidade de se produzir pelo menos 4.380 litros/ano com uma taxa de lotação de no mínimo 1,0 vaca em lactação por hectare, considerando toda a área destinada ao rebanho leiteiro. A quantidade de leite produzida por hectare e a quantidade de matrizes por hectare, evidenciam que as áreas das propriedades nos municípios analisados, estão com suas capacidades de utilização ociosas. Visto que a relação vaca em lactação:vaca total aliada ao número de vacas por hectare, indica a capacidade de produção por área, que está diretamente associada à uma boa lucratividade.

As diferenças tecnológicas verificadas neste estudo, entre os municípios do Cariri paraibano, demonstram o grau de pluralidade existente entre os sistemas de produção de leite.

Com este estudo foi possível encontrar informações importantes para tomada de decisões no contexto atual da pecuária leiteira, capaz de identificar alguns pontos de estrangulamento da atividade. A partir das informações obtidas, ações específicas para cada situação de produção de leite, podem ser desenvolvidas com objetivo de promover o incremento da qualidade $\mathrm{e}$ quantidade do leite produzido.

Os produtores de Barra de Santana pareceram ser mais eficientes no processo produtivo, pois em menor área criam mais animais por hectare, apresentam produtividade semelhante aos de Caturité e produzem uma maior quantidade de leite por hectare/ano, mesmo sem cultivar sorgo, com menor área de palma, com rebanho mais azebuado e menor assistência técnica. Portanto, é necessária a realização de um estudo econômico nas propriedades de Barra de Santana, a exemplo do que foi realizado nas propriedades Caturité, para realmente comprovar qual sistema de produção é mais eficiente.

\section{REFERÊNCIAS}

AGÊNCIA EXECUTIVA DE GESTÃO

DAS ÁGUAS DO ESTADO DA

PARAIIBA - AESA. Monitoramento das precipitações pluviométricas do Estado da Paraíba. Disponível em:

$<$ http://www2.aesa.pb.gov.br/meteoro/pcdl mrs.shtml>. Acesso em: 26 out. 2007.

CAMPOS, M.C.C.; QUEIROZ, S.B. Reclassificação dos perfis descritos no levantamento exploratório-reconhecimento de solos do estado da paraíba. Revista de Biologia e Ciências da Terra, v.6, n.1, p.45-50, 2006.

COSTA, R.G.; DAL MONTE, H.L.B.; PIMENTA FILHO, E.C.; HOLANDA JUNIOR, E.V.; CRUZ, G.R.B.; MENEZES, M.P.C. Typology and characterization of goat milk production systems in the Cariris Paraibanos. Revista Brasileira de Zootecnia, v.39, p.656-666, 2010.

COSTA, R.G.; ALMEIDA, C.C.; PIMENTA FILHO, E.C.; HOLANDA JUNIOR, E.V.; SANTOS, N.M. Caracterização do sistema de produção caprino e ovino na região Semi-Árida do estado da Paraíba. Brasil. Archivos de Zootecnia, v.57, p.195-205, 2008.

EMPRESA BRASILEIRA DE PESQUISA AGROPECUÁRIA - EMBRAPA. Sistema brasileiro de classificação de solos.

Brasília, DF, 1999. 128p.

FRANCA, F.M. C.; HOLANDA JUNIOR, E.V.; SOUSA NETO, J.M. Análise da viabilidade financeira e econômica do modelo de exploração de ovinos e caprinos no Ceará por meio do Sistema Agrossilvipastoril. Revista Econômica do Nordeste, v.42, p.287-307, 2011.

GOMES, A.T. Gerenciamento na atividade leiteira. Jornal da Produção de Leite, v.12, n.197, p.254-261, 2005. 
GOMES, S.T. Efeitos da globalização na produção de leite do Brasil. Informe Agropecuário, v.20, n.199, p.93-102, 2002.

GUILHERMINO, M.M.; FREITAS, A.R. Sistemas informatizados para rebanhos leiteros: quem são seus usuários? Archivo Latinoamericano de Produção Animal, v.8, n.2, p.69-75, 2000.

GUILHERMINO, M.M.; GROSSI, S.F. Técnicas de inquérito na produção animal. Boletim de Indústria Animal, v.53, n.1, p.91-98, 1996.

LEITE, R.H.M.; LAGE, A.P.; JAYME, V.S.; MODENA, C.M. Perfil produtivosanitário de propriedades produtoras de bovinos do Estado da Paraíba, Brasil. Ciência Animal Brasileira, v.5, n.4, p.199-209, 2004.

LOPES JUNIOR, OLIVEIRA, C.J.B; QUEIROGA, R.C.R.E., MOURA, J.F.P.; MONTE, D.F.M.; MENEZES, L.M.; BARBOSA, C.M. Avaliação microbiológica e contagem de células somáticas em leite bovino in natura produzido no Cariri paraibano. In: CONGRESSO BRASILEIRO DE QUALIDADE DO LEITE, 3., 2008, Recife. Anais... Recife: UFRPE, 2008. p.125-128.

LOPES, M.A.; ALMEIDA JÚNIOR, G.A.; CARVALHO, F.M.; SOUSA, M.; RINO, M.C.P.B. Rentabilidade de um sistema de produção de leite tipo B: um estudo de caso com a raça Jersey, no Estado de São Paulo. Revista Economia Rural, v.14, n.2, p.11-16, 2003.
LIMA, P.J.S.; FIGUEIREDO, M.V.; MOURA, J.F.P.; GOMES, J.T.; RIBEIRO, M.N.; PIMENTA FILHO, E.C. Gestão genética de raças caprinas nativas no Estado. Archivos de Zootecnia, v.56, p.623-626, 2007. Supl.1.

OLIVEIRA, A.S.; CUNHA, D.N.F.V.; CAMPOS, J.M.S.; VALE, S.M.L.R.; ASSIS, A.J. Identificação e quantificação de indicadores-referência de sistemas de produção de leite. Revista Brasileira de Zootecnia, v.36, n.2, p.507-516, 2007.

SAMPAIO, I.B.M. Estatística aplicada à experimentação animal. 2.ed. Belo Horizonte-MG: Fundação de Estudo e Pesquisa em Medicina Veterinária e Zootecnia, 2002. 265p.

SCHIFFLER, E.A.; MÂNCIO, A.B.; GOMES, S.T.; QUEIROZ, A.C. Efeito da escala de produção nos resultados econômicos da produção de leite $\mathrm{B}$ no Estado de São Paulo. Revista Brasileira de Zootecnia, v.28, n.2, p.425-431, 1999.

SILVA, C.C.F; SANTOS, L.C. Palma Forrageira (Opuntia Fícus- Indica Mill) como alternativa na alimentação de ruminantes. Revista Eletrônica de Veterinária, v.7, n.10, p.34-48, 2006.

Data de recebimento: 01/06/2012

Data de aprovação: 19/12/2012 